\title{
Low concentrations of monosodium glutamate (MSG) are safe in male Drosophila melanogaster
}

\author{
Keneth Iceland Kasozi ${ }^{*}$, Sarah Namubiru ${ }^{2}$, Oliver Kiconco ${ }^{3}$, Hellen Wambui Kinyi ${ }^{4}$, Fred Ssempijja ${ }^{5}$, \\ Joseph Obiezu Chukwujekwu Ezeonwumelu ${ }^{3}$, Herbert Izo Ninsiima ${ }^{1}$ and Alfred Omachonu Okpanachi ${ }^{1}$
}

\begin{abstract}
Objective: Monosodium glutamate (MSG) has been marred by a lot of controversy on its safety. In a majority of experimental studies, administration of the compound has been parenteral, and yet little is known about MSG safety consumed as a food supplement. In this study, we assessed the effects of low concentrations of MSG on the activity of hydrogen scavenging, catalase activity and climbing as well as lifespan in male Drosophila melanogaster over a 30 days period since this has been sparsely studied.

Results: No significant differences were associated with MSG at $5 \%, 1 \%, 0.2 \%, 0.04 \%$ on hydrogen peroxide scavenging, negative geotaxis and lifespan in $W^{1118}$ male D. melanogaster. Significant differences were found in 5\% MSG on catalase activity, showing that high MSG concentrations would affect tissue health in male D. melanogaster. MSG consumed as a food supplement would be safe at concentrations below 5\% MSG.
\end{abstract}

Keywords: Drosophila melanogaster, MSG Safety, MSG toxicity, Catalase activity

\section{Introduction}

Monosodium glutamate (MSG) is a common household food seasoning and its use has stirred a lot of controversy [1], although it has already received approval by international food regulatory agencies [2-4]. In a majority of experimental studies, MSG has been associated with oxidative stress [5], although these findings have been difficult to reproduce [6], thus fueling the controversy. This is because MSG is a salt of glutamate which is important in the Krebs pathway [7]. In addition, glutamate is common to foods eaten daily and its readily absorbed in the gut [8]. Furthermore, epidemiological studies have failed to identify the causative effects of the side-effects claimed to be associated with MSG $[9,10]$, showing a need to gain clear insight on its safety. A study by Abolaji [11] has associated low MSG concentrations in Drosophila melanogaster with toxicities due to its high oxidative stress,

\footnotetext{
*Correspondence: kicelandy@gmail.com

1 Department of Physiology, Faculty of Biomedical Sciences, Kampala International University Western Campus, Box 71, Bushenyi, Uganda Full list of author information is available at the end of the article
}

and reduced lifespan effects in a 5 days study, however, information over longer durations of exposure is limited. Bearing in mind that D. melanogaster have an established toxicological advantage due to their large population numbers and short lifecycle $[12,13]$, there was a need to examine MSG exposure in D. melanogaster over a longer period. In addition, oxidative stress in $D$. melanogaster has been found to decrease with an increase in age [14], showing the role of the experimental period in toxicological evaluation of MSG. The objective of the study was to determine effects of MSG supplementation on hydrogen peroxide scavenging activity, catalase activity, negative geotaxis, and lifespan in male D. melanogaster.

\section{Main text \\ Methods}

Monosodium glutamate (99\%) was acquired from Ajinomoto Co. Inc, (Tokyo) Japan through the Institute for Innovation. Fly food was prepared in line with manufacturer recommendations [15]. In brief, 4 food types were prepared by supplementing regular fly food with 
MSG in the following concentration, i.e. 5\% w/w MSG $[4,16], 1 \% \mathrm{w} / \mathrm{w}$ MSG and $0.2 \% \mathrm{w} / \mathrm{w}$ MSG [11], and $0.04 \%$ w/w MSG, and a control group. Drosophila melanogaster $W^{1118}$ strains were acquired from the Bloomington Fly Stock Center, USA and these were cultured to build sufficient colonies at the Institute of Biomedical Research, Kampala International University Western Campus. From the stock population, virgin females and young males were placed on fresh food and allowed to mate. Fresh eggs were collected, and dated to ensure that the dates of birth are synchronized for all flies. In each experimental group, five replicas were created, with each vial consisting of 10 flies (i.e. $n=5 \times 10=50$ ), for each experiment. For all experiments, $\mathrm{N}=50$ flies $\times 5$ groups $\times 4$ experimental groups $=1000$ flies. Flies were allowed to feed for a period of 30 days.

\section{Hydrogen scavenging and catalase activity determination}

Drosophila melanogaster flies from different experimental groups were anesthetized on ice and homogenized in $0.1 \mathrm{M}$ phosphate buffer, pH $7.0(1 \mathrm{mg}: 10 \mu \mathrm{L})$. Samples were further processed as previously described [11]. After centrifugation at $4000 \times g$ for $10 \mathrm{~min}$, the supernatant was placed into sterile Eppendorf tubes and used for biochemical experimentation at the end of the experimental period.

Catalase activity was determined by measuring the decrease in the absorbance of $\mathrm{H}_{2} \mathrm{O}_{2}$ $\left(\varepsilon=39.4 \mathrm{mM}^{-1} \mathrm{~cm}^{-1}\right)$ at $320 \mathrm{~nm}$ after a reaction mixture containing $500 \mu \mathrm{L}$ of $50 \mathrm{mM}$ phosphate buffer $(\mathrm{pH}$ 7.0), $180 \mu \mathrm{L}$ of $300 \mathrm{mM} \mathrm{H}_{2} \mathrm{O}_{2}$, and $20 \mu \mathrm{L}$ of sample was made to react for $2 \mathrm{~min}$ [11]. The decrease in absorbance of $\mathrm{H}_{2} \mathrm{O}_{2}\left(\varepsilon=39.4 \mathrm{mM}^{-1} \mathrm{~cm}^{-1}\right)$ at $320 \mathrm{~nm}$ was recorded $2 \mathrm{~min}$ after a reaction mixture containing $500 \mu \mathrm{L}$ of $50 \mathrm{mM}$ phosphate buffer ( $\mathrm{pH} 7.0), 180 \mu \mathrm{L}$ of $300 \mathrm{mM}$ $\mathrm{H}_{2} \mathrm{O}_{2}$, and $20 \mu \mathrm{L}$ of sample. Catalase activity was then measured and expressed as micromoles of $\mathrm{H}_{2} \mathrm{O}_{2}$ decomposed per minute per milligram of protein. Furthermore total protein was also determined [17].

The ability of the Drosophila to scavenge hydrogen peroxide was determined according to the well-documented method [18] with minor modifications. In brief, $40 \mathrm{mM}$ of $\mathrm{H}_{2} \mathrm{O}_{2}$ were prepared in phosphate buffer at a $\mathrm{pH}$ 7.4. To improve on the concentration of $\mathrm{H}_{2} \mathrm{O}_{2}$ from the supernatant of $D$. melanogaster, centrifugation was repeated at $16,000 \times g$ and the refined supernatant $(10 \mu \mathrm{g} /$ $\mathrm{mL}$ ) were mixed with $0.6 \mathrm{~mL}$ of $40 \mathrm{mM} \mathrm{H}_{2} \mathrm{O}_{2}$. Absorbance was taken at $320 \mathrm{~nm}$ after 10 min against a blank solution containing phosphate buffer [19]. A total of 10 flies were used in each vial, and these were kept in 5 replicas for each experimental group $(n=5)$. The percentage of hydrogen peroxide scavenging of both $D$. melanogaster and standard was determined using the equation;
\% scavenging $\left[\mathrm{H}_{2} \mathrm{O}_{2}\right]=\left[\left(\mathrm{A}_{\mathrm{c}}-\mathrm{A}_{\mathrm{s}}\right) / \mathrm{A}_{\mathrm{c}}\right] \times 100$;

where $A_{c}$ is the absorbance of the control and $A_{s}$ is the absorbance in the presence of the sample and standards.

\section{Locomotion and lifespan determination}

Locomotion determination was done using the negative geotaxis experiment as described by Niveditha [14] at the end of the MSG feed exposure period. A transparent plastic ring tube which would hold 10 flies at once of standard length, $25 \mathrm{~cm}$ was secured on a tripod stand. In brief, the tube was tapped gently to allow the flies to settle at the bottom and a timer was started, at the moment when they were allowed to climb. The total number of flies that moved above the $12 \mathrm{~cm}$ mark in $20 \mathrm{~s}$ were counted. This was repeated for all replicas in each experimental group and the mean number was taken as the number of flies which performed positively in the experiment, and these were expressed as a percentage for each group.

Lifespan study was conducted for male fly cultures at $25{ }^{\circ} \mathrm{C}, 60-65 \%$ humidity and a $12 \mathrm{~h}$ light $/ 12 \mathrm{~h}$ dark cycle in a climate-controlled incubator and the number of dead flies were counted every 3 days for a period of 30 days $[20,21]$.

\section{Statistical analysis}

Data was analyzed with Graph Pad prism 6, and presented as graphs. Factorial analysis of variance (ANOVA) was performed to test the interactions among treatment dosages using a Tukey's multiple comparison test for all experiments, expect the lifespan data which was analyzed using Kaplan-Meier survival analysis and Mantel-Cox was performed on the survival curves, with significance being reported when $P<0.05$.

\section{Results}

The ability for Drosophila to scavenge hydrogen peroxide was low during different MSG exposure concentrations $(\mathrm{P}>0.05)$ as shown in Fig. 1a. In addition, catalase activity was found to be lowest in the 5\% MSG exposed male flies $(\mathrm{P}<0.05)$ in comparison to the control as shown in Fig. 1b.

There were no significant changes in the geotaxis (Fig. 2a) although 5\% MSG had a higher climbing index. In addition, survival was higher in the $0.2 \%$ and $0.04 \%$ MSG in comparison to 5\% and 1\% MSG (Fig. 2b). No significant differences were associated with lifespan, negative geotaxis and scavenging activity during this experimental period (Table 1).

\section{Discussion}

Low levels of MSG had no significant changes on hydrogen peroxide (Fig. 1a), which is key in the formation of 


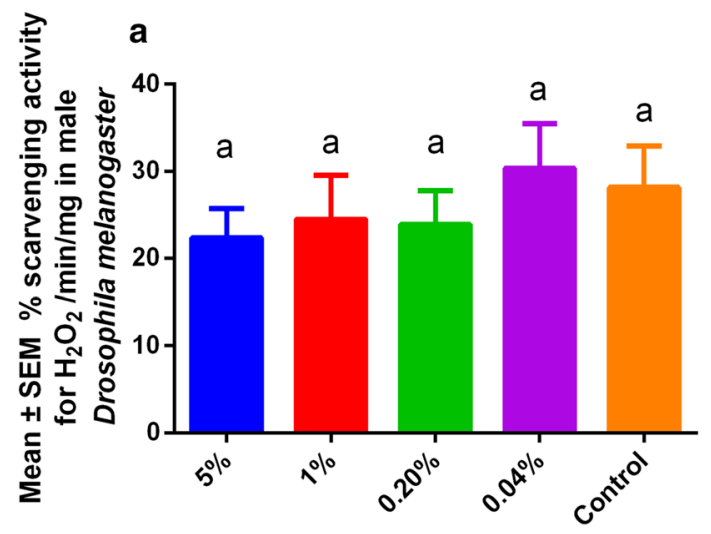

Concentrations of MSG

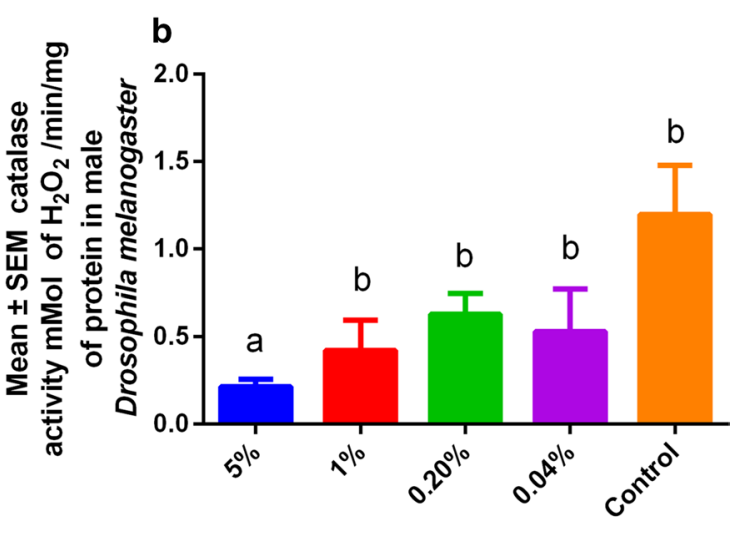

Concentrations of MSG

Fig. 1 Effects of MSG in male Drosophila melanogaster. a Scavenging activity of hydrogen peroxide. b Catalase activity

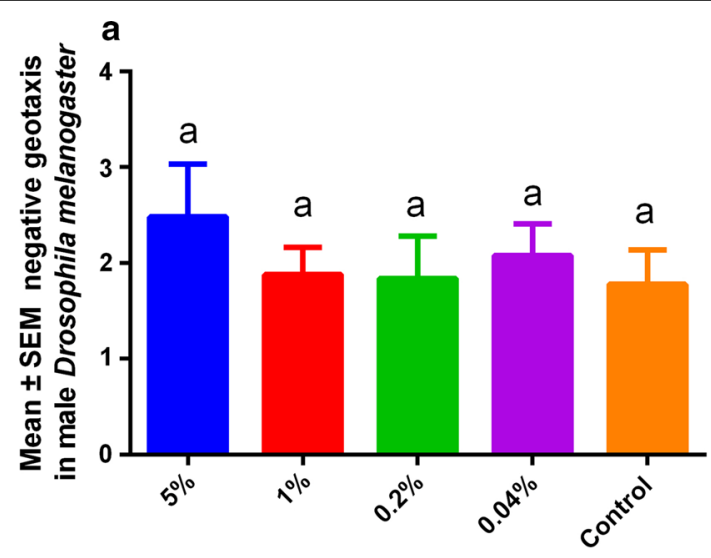

b

Monosodium glutamate concentrations

Fig. 2 Negative geotaxis and lifespan in male Drosophila melanogaster

Table 1 Multiple comparisons between experimental groups for negative geotaxis, catalase, scavenging and lifespan activity in male Drosophila melanogaster

\begin{tabular}{|c|c|c|c|c|c|}
\hline $\begin{array}{l}\text { Tukey's multiple } \\
\text { comparisons test }\end{array}$ & $\begin{array}{l}\text { Number of flies } \\
\text { per group (N) }\end{array}$ & $\begin{array}{l}\text { Negative geotaxis } \\
\text { Adjusted } P \text { values }\end{array}$ & Catalase activity & Scavenging activity & Lifespan \\
\hline $5 \%$ vs. $1 \%$ & 50 & 0.8305 & 0.9396 & 0.9973 & \multirow{10}{*}{$\begin{array}{l}\text { Log-rank (Mantel-Cox) test for curve com- } \\
\text { parisons; } X^{2}(4)=3.644, P=0.4563\end{array}$} \\
\hline $5 \%$ vs. $0.2 \%$ & 50 & 0.7950 & 0.5285 & 0.9992 & \\
\hline $5 \%$ vs. $0.04 \%$ & 50 & 0.9554 & 0.7355 & 0.7180 & \\
\hline $5 \%$ vs. control & 50 & 0.7368 & $0.0088^{*}$ & 0.8915 & \\
\hline $1 \%$ vs. $0.2 \%$ & 50 & $>0.9999$ & 0.9427 & $>0.9999$ & \\
\hline $1 \%$ vs. $0.04 \%$ & 50 & 0.9967 & 0.9943 & 0.8845 & \\
\hline $1 \%$ vs. control & 50 & 0.9998 & 0.0706 & 0.9773 & \\
\hline $0.2 \%$ vs. $0.04 \%$ & 50 & 0.9933 & 0.9952 & 0.8476 & \\
\hline $0.2 \%$ vs. control & 50 & $>0.9999$ & 0.2581 & 0.9626 & \\
\hline $0.04 \%$ vs. control & 50 & 0.9843 & 0.1165 & 0.9967 & \\
\hline
\end{tabular}

$P$ values acquired from one-way ANOVA, "**" represents significant difference 
reactive oxygen species [11]. These observations show that MSG at low concentrations would have enhanced antioxidant activity (Fig. 1b), demonstrating the safety of MSG once consumed in food due to its beneficial effects, which is in agreement with previous findings [22]. Bearing in mind that domestic usage of MSG has been internationally recommended [1-4]. The increased oxidative stress associated with lower concentrations of MSG [6], would be difficult to reproduce once its administered parenteral and at high concentrations as reported in several experimental studies [5]. Furthermore, adaptive responses associated with MSG at concentrations used by Abolaji [11] were not reproducible, showing the relevance of the current study.

The study also showed that low concentrations of MSG did not significantly affect the climbing index (Fig. 2a). This was important since MSG contains glutamate which is readily absorbed in the gut and assimilated into the Krebs cycle during energy production [7, 8]. Increased energy production would subsequently be associated with increased glucose breakdown, and production of more reactive oxygen species [23], leading to a decrease in antioxidant activity (Fig. 1b). Finally, lifespan was not affected by MSG at low concentrations used in the study (Fig. 2b), showing that MSG was safe in D. melanogaster. These findings show that effects of MSG on lifespan would be due to the high concentrations (i.e. 10\%-20\%) with are above safe concentrations recommended for humans [24], showing the wisdom of using small concentrations in foods. The lack of significant effects (Table 1) at these concentrations would offer a basis as to why no epidemiological data has been able to associate MSG successful with patient outcomes since humans, often consume the compound in very small concentrations, showing a need for a clinical study.

\section{Limitations}

More information would be acquired by including more antioxidants and oxidative stress markers as we were unable to investigate them, however, this study provides basic information on the safety of low concentrations of MSG. Furthermore, information from female D. melanogaster would offer further insights on any toxicological effects which may be gender related.

\section{Abbreviations \\ $\mathrm{H}_{2} \mathrm{O}_{2}$ : hydrogen peroxide; mM: millimoles; MSG: monosodium glutamate; $\mathrm{W} / \mathrm{W}$ : weight by weight; $\mu \mathrm{L}$ : microliters.}

\section{Authors' contributions}

KIK; and SN designed the study, KIK; OK; HWK; FS collected the data; KIK; OK; $\mathrm{SN} ; \mathrm{HWK}, \mathrm{FS} ; \mathrm{JOCE} ; \mathrm{HIN}$ and AOO conducted data analysis and interpretation.
KIK; SN; OK; HWK; FS; JOCE; HIN; AOO interpreted results, wrote, revised initial and final manuscript. All authors read and approved the final manuscript.

\section{Author details \\ ${ }^{1}$ Department of Physiology, Faculty of Biomedical Sciences, Kampala Inter- national University Western Campus, Box 71, Bushenyi, Uganda. ${ }^{2}$ College of Veterinary Medicine Animal Resources and Biosecurity, Makerere University, Box 7062, Kampala, Uganda. ${ }^{3}$ Department of Clinical and Biopharmacy, School of Pharmacy, Kampala International University Western Campus, Box 71, Bushenyi, Uganda. ${ }^{4}$ Department of Biochemistry, Faculty of Biomedi- cal Sciences, Kampala International University Western Campus, Box 71, Bushenyi, Uganda. ${ }^{5}$ Department of Anatomy, Faculty of Biomedical Sciences, Kampala International University Western Campus, Box 71, Bushenyi, Uganda.}

\section{Acknowledgements}

Authors wish to thank the assistance offered by Dr. Marta Vicente-Crespo for her technical support and Sayansi IXD and DrosAfrica that supported the establishment of the Institute of Biomedical Research at KIU with materials, equipment and training workshops. Furthermore, authors wish to acknowledge the support of Dr. Sharon Juliano under the Teaching Tools Workshops in Africa as well as Trends in Africa for their mentorship training and constructive criticism.

\section{Competing interests}

The authors declare that they have no competing interests.

\section{Availability of data and materials}

Information used in the study can be accessed at https://figshare.com/s/a22fd f03c861709ebf5c.

\section{Consent to publish \\ Not applicable.}

\section{Ethical approval and consent to participate}

This was acquired from the Kampala International University Western Campus Ethics and Scientific review board. Consent to participate was not applicable for this study.

\section{Funding}

Not applicable.

\section{Publisher's Note}

Springer Nature remains neutral with regard to jurisdictional claims in published maps and institutional affiliations.

Received: 21 July 2018 Accepted: 10 September 2018

Published online: 17 September 2018

\section{References}

1. Kazmi Z, Fatima I, Perveen S, Malik SS. Monosodium glutamate: review on clinical reports. Int J Food Prop. 2017;20:1807-16.

2. Xiong JS, Branigan D, Li M. Deciphering the MSG controversy. Int J Clin Exp Med. 2009;2(4):329-36.

3. Kemp SE, Beauchamp GK. Flavor modification by sodium chloride and monosodium glutamate. J Food Sci. 1994:59(3):682-6.

4. JECFA. Evaluation of certain contaminants in food. World Health Organisation Technical Report Series no. 959, back cover; 2011. p. 1-105.

5. Collison KS, et al. Effect of dietary monosodium glutamate on HFCSinduced hepatic steatosis: expression profiles in the liver and visceral fat. Obesity (Silver Spring). 2010;18(6):1122-34.

6. Yoneda J, Chin K, Torii K, Sakai R. Effects of oral monosodium glutamate in mouse models of asthma. Food Chem Toxicol. 2011:49(1):299-304.

7. Sanchez S, Demain AL. Review metabolic regulation and overproduction of primary metabolites. Microb Biotechnol. 2008;1 (4):283-319.

8. Burrin DG, Stoll B. Metabolic fate and function of dietary glutamate in the gut. Am J Clin Nutr. 2009;90(3):850-6.

9. VuThiThu H, Wakita A, Shikanai S, Iwamoto T, Wakikawa N, Shigeru Yamamoto. (2013) Epidemiological Studies of Monosodium Glutamate 
and Health. J Nutr Food Sci S10:009. https://doi.org/10.4172/2155-9600. S10-009

10. Jinap S, Hajeb P. Glutamate. Its applications in food and contribution to health. Appetite. 2010;55(1):1-10.

11. Abolaji AO, Olaiya CO, Oluwadahunsi OJ, Farombi EO. Dietary consumption of monosodium L-glutamate induces adaptive response and reduction in the life span of Drosophila melanogaster. Cell Biochem Funct. 2017. https://doi.org/10.1002/cbf.3259.

12. Potter S, Krall RM, Mayo S, Johnson D, Cooper RL. Population dynamics based on resource availability \& founding effects: live \& computational models life cycle of the fruit fly \& the population modules fruit flies are used as a model organism in research laboratories and classrooms preparation procedure. Am Biol Teach. 2016;78(5):396-403.

13. Jennings BH. Drosophila-a versatile model in biology and medicine. Mater Today. 2011;14(5):190-5.

14. Niveditha S, Deepashree S, Ramesh SR, Shivanandappa T. Sex differences in oxidative stress resistance in relation to longevity in Drosophila melanogaster. J Comp Physiol B. 2017;187:899-909.

15. Wong R, Piper MDW, Wertheim B, Partridge L. Quantification of food intake in Drosophila. PLoS ONE. 2009. https://doi.org/10.1371/journ al.pone.0006063.

16. Deepak D, Krishna SM. Effect Of chronic exposure of monosodium glutamate (MSG) on viability and rate of feeding in two different strains of Drosophila Melanogaster. Int J Recent Sci Res. 2015;6(6):4483-5.
17. Lowry OH, Nira JR, Farr AL, Rose JR. Protein measurement with the folin phenol reagent. J Biol Chem. 1951;193:265-75.

18. Ruch RJ, Cheng SJ, Klaunig JE. Prevention of cytotoxicity and inhibition of intercellular communication by antioxidant catechins isolated from chinese green tea. Carcinogenesis. 1989;10(6):1003-8.

19. Sasikumar V. Evaluation of free radical scavenging activity of various leaf extracts from Kedrostis foetidissima (Jacq.) Cogn. Biochem. Anal Biochem. 2014;3(2):1.

20. Piper MDW, Partridge L. Protocols to study ageing in Drosophila. Methods Mol Biol. 2016;1478:291-302.

21. Linford NJ, Bilgir C, Ro J, Pletcher SD. Measurement of lifespan in Drosophila melanogaster. J Vis Exp. 2013;71:1-9.

22. Lopez-Miranda V, et al. Effects of chronic dietary exposure to monosodium glutamate on feeding behavior, adiposity, gastrointestinal motility, and cardiovascular function in healthy adult rats. Neurogastroenterol Motil. 2015;27(11):1559-70.

23. Liemburg-Apers DC, Willems PHGM, Koopman WJH, Grefte S. Interactions between mitochondrial reactive oxygen species and cellular glucose metabolism. Arch Toxicol. 2015;89(8):1209-26.

24. Yong JC, Hae JH. A study of the effect of monosodium glutamate on the development of Drosophila melanogaster. Korean J. Zool. 1973:16(2):127-38.
Ready to submit your research? Choose BMC and benefit from:

- fast, convenient online submission

- thorough peer review by experienced researchers in your field

- rapid publication on acceptance

- support for research data, including large and complex data types

- gold Open Access which fosters wider collaboration and increased citations

- maximum visibility for your research: over 100M website views per year

At BMC, research is always in progress.

Learn more biomedcentral.com/submissions 